\title{
Application of Femtosecond Laser Mass Spectrometry to the Analysis of Volatile Organic Compounds
}

\author{
Min Liu, ${ }^{a}$ Chengyin $\mathrm{Wu}^{,}{ }^{\mathrm{a}}$ Zhifeng $\mathrm{Wu},{ }^{\mathrm{a}}$ Hong Yang, ${ }^{\mathrm{a}}$ Qihuang Gong, ${ }^{\mathrm{a}}$ \\ Wei Huang, ${ }^{b}$ and Tong Zhu ${ }^{\mathrm{b}}$ \\ a State Key Laboratory for Mesoscopic Physics, Department of Physics, Peking University, Beijing 100871, \\ People's Republic of China \\ ${ }^{\mathrm{b}}$ Center for Environment and Health, Peking University, Beijing 100871, People's Republic of China
}

\begin{abstract}
Femtosecond (fs) lasers have high intensity and ultrashort pulse duration. Tunneling ionization occurs for molecules subject to such intense laser fields. We have studied the mass spectra of a variety of molecules irradiated by intense fs laser pulses. These molecules include some typical volatile organic compounds contained in human breath and in the atmosphere. The results demonstrate that all of these molecules can be ionized by intense fs laser pulses. Dominant parent ion and some characteristic ionic fragments are observed for each molecule. The degree of fragmentation can be controlled by adjusting the laser intensity. Moreover, saturation ionization can occur for each molecule by increasing the laser intensity. These features indicate that fs laser mass spectrometry can be a sensitive tool to identify and quantify volatile organic compounds in human breath. (J Am Soc Mass Spectrom 2010, 21, 1122-1128) (c) 2010 American Society for Mass Spectrometry
\end{abstract}

$\mathrm{V}$ olatile organic compounds (VOCs) have sufficiently high vapor pressures under normal conditions to significantly vaporize. Some of these compounds are major pollutants in the atmosphere, the environment, groundwater, food, and indoor air [1-6]. VOCs can cause damage to human health when they are absorbed through the skin or taken up via inhalation or ingestion into the human body. For example, the prolonged exposure to VOCs in the indoor environment might increase the risk of leukemia and lymphoma [7]. Therefore, VOCs are regulated in some places.

VOCs are also important components in the exhaled air of human beings. Some VOCs in human breath are derived from the environment, while others are generated in the body as products of metabolic processes or the activity of intestinal bacteria [8]. The compositions and concentrations of exhaled breath are different between patients and healthy people [9-11]. Associations between the concentrations of some VOCs in exhaled breath and the occurrence of certain diseases have been demonstrated. Therefore, some VOCs can serve as biomakers for diseases. For example, exhaled methyl nitrate can be used as a noninvasive marker of hyperglycemia in type 1 diabetes [9]. Combination of several exhaled markers may enable recognition and diagnosis of complex diseases such as tumors or cancer $[10,11]$.

Address reprint requests to Professor C. Wu, Department of Physics, Peking University, Beijing 100871, P.R. China. E-mail: cywu@pku.edu.cn
To identify appropriate exhaled markers for diseases of interest for potential clinical applications, the detection techniques for hundreds of VOCs in exhaled breath must be improved for sensitivity and specificity. Many sensitive VOC analytical technologies have been developed to identify and quantify these trace VOCs in human exhaled air [12-15]. Gas chromatography can separate different volatile compounds and mass spectrometry can identify them [16]. Therefore, gas chromatography mass spectrometry (GC/MS) is commonly used in analyzing human exhaled breath. Even though extensive information about the composition of VOCs can be obtained using GC/MS analysis, there are limitations in this technique. First, both sampling and preconcentration before gas chromatography can lead to contamination problems for VOCs in human exhaled air. Secondly, mass spectrometry with electron impact results in many ionic fragments and makes the identification difficult. In addition to GC/MS, proton transfer reaction mass spectrometry (PTR-MS) is also widely used for measurement of VOCs $[17,18]$. In contrast to GC/MS, the soft ionization technique in PTR-MS does not require the separation step and can detect trace VOCs online. However, proton transfer reactions can occur only for those VOCs whose proton affinities are higher than that of water. Moreover, since there is less fragmentation, PTR-MS cannot discriminate those molecules of the same molecular mass [19]. In this article, we use femtosecond (fs) laser mass spectrometry (FLMS) to analyze VOCs that occur in human breath. The results demonstrate that the parent ion and some significant 
characteristic ionic fragments are produced with FLMS. In addition, the ionization efficiency can reach unity for molecules in an intense fs laser field. Therefore, FLMS combines the advantages of GC/MS and PTR-MS. It is a potentially powerful tool to identify and quantify the trace VOCs contained in human breath.

\section{Principle}

Femtosecond lasers have high laser intensity $\left(>10^{14}\right.$ $\left.\mathrm{W} / \mathrm{cm}^{2}\right)$ and ultrashort pulse duration $(<100 \mathrm{fs})$. The electric field in a focused fs laser beam can be comparable to the molecular Coulombic field $\left(\sim 10^{8} \mathrm{~V} / \mathrm{cm}\right)$ felt by valence electrons. The external field asymmetrically distorts the potential and forms a potential barrier on one side of the molecule. The electron in the highest occupied molecular orbit tunnels through the barrier, which leads to field ionization of the molecules [20, 21], a type of soft ionization. The intense $800 \mathrm{~nm}$ fs laser can ionize all molecules and the parent ion is dominant, even for labile molecules [22-27]. The advantages of FLMS and its possible applications have been summarized in the review article [22]. The ionization probability depends on the laser intensity and the ionization energy of the molecules. To achieve the same ionization probability, a higher laser intensity is needed for a molecule with a high ionization energy. The molecule can be pumped to a highly excited state, and the parent ion might dissociate to form ionic fragments. The time scale of bond cleavage is several tens of femtoseconds for molecules [28, 29]. The neutral fragments cannot be ionized further because the laser pulse has ended. Therefore, the ionic fragments observed in FLMS originate from the direct dissociation of the parent ions. The parent ion and characteristic ionic fragments provide identification of the molecule. In addition, the intense laser can ensure that all molecules within the laser focus are ionized [20]. Therefore, the ion yield directly represents the concentration of molecules. These features demonstrate that FLMS is a potentially sensitive tool to identify and quantify the trace VOCs in human breath.

\section{Experimental}

The experimental setup has been described in detail in our previous papers [30]. A commercial fs laser amplifier (Femtolasers Productions $\mathrm{GmbH}$, Vienna, Austria) delivers laser pulses with a central wavelength of 780 $\mathrm{nm}$ at a repetition rate of $3 \mathrm{kHz}$. The $30 \mathrm{fs}$ laser pulse is then broadened by a $1 \mathrm{~m}$ hollow fiber filled with $2 \mathrm{~atm}$ argon. The laser beam is recompressed by chirped mirrors after collimation by a $1 \mathrm{~m}$ concave silver mirror. The laser duration is $7 \mathrm{fs}$ and the central wavelength is $750 \mathrm{~nm}$ after compression. The $110 \mathrm{fs}$ laser pulse is produced by another Ti:sapphire fs laser system with a regenerative chirp pulse amplifier (TSA-10; SpectraPhysics Inc., Mountain View, CA, USA). The central wavelength of the pulse is $800 \mathrm{~nm}$ and the repetition is $10 \mathrm{~Hz}$. The spectrum and pulse duration are monitored by a commercial spectrometer and an interferometric autocorrelator, respectively. The laser beams are focused by a concave mirror with a focal length of 250 $\mathrm{mm}$ into a time-of-flight spectrometer. The gaseous sample or the vapor of a liquid sample contained in a stainless cell is introduced into the chamber by a pulsed valve (Park Inc., Cleveland, OH, USA) with a $0.2 \mathrm{~mm}$ orifice. The ions produced by the laser pulses are accelerated by a two-stage electric field and collected by a microchannel plate. The mass spectra averaging over 256 laser pulses are recorded by a $1 \mathrm{GHz}$ data acquisition card (DP110; Acqiris Digitizers, Geneva, Switzerland).

\section{Results and Discussion}

We have investigated several kinds of organic molecules with fs laser mass spectrometry. These molecules include alcohols, ketones, alkanes, esters, etc. Table 1 lists their formulas, molecular masses, and ionization energies. Research has indicated that these molecules are contained in human breath, and some of them are related to diseases. For example, acetone is linked to dextrose metabolism and lipolysis [8]. Exhaled ethane is found to be elevated in inflammatory diseases [8]. We also recorded mass spectra of the main components of air $\left(\mathrm{N}_{2}, \mathrm{O}_{2}, \mathrm{CO}_{2}\right)$ and some pollutants of air $\left(\mathrm{CO}\right.$ and $\mathrm{CS}_{2}$ ).

\section{Alcohols}

Figure 1 shows the mass spectra of methanol and ethanol irradiated by $110 \mathrm{fs}$ laser pulses at an intensity of $1.0 \times 10^{14} \mathrm{~W} / \mathrm{cm}^{2}$. For methanol, the peak at $\mathrm{m} / \mathrm{q}=$ 32 is the parent ion $\mathrm{CH}_{3} \mathrm{OH}^{+}$. The peak at $\mathrm{m} / \mathrm{q}=31$, $\mathrm{CH}_{2} \mathrm{OH}^{+}$, arises from dissociation of the $\mathrm{C}-\mathrm{H}$ bond of the parent ion [31]. For ethanol, the peak at $\mathrm{m} / \mathrm{q}=46$ is the parent ion $\mathrm{C}_{2} \mathrm{H}_{5} \mathrm{OH}^{+}$. The peak at $\mathrm{m} / \mathrm{q}=45$ is

Table 1. Molecular parameters

\begin{tabular}{llcc}
\hline \multicolumn{1}{c}{ Gas } & \multicolumn{1}{c}{ Formula } & Mass & $\begin{array}{c}\text { lonization } \\
\text { energy }(\mathrm{eV})\end{array}$ \\
\hline \hline Methanol & $\mathrm{CH}_{3} \mathrm{OH}$ & 32 & 10.85 \\
Alcohol & $\mathrm{C}_{2} \mathrm{H}_{5} \mathrm{OH}$ & 46 & 10.4 \\
Acetone & $\mathrm{CH}_{3} \mathrm{COCH}_{3}$ & 58 & 9.7 \\
Butanone & $\mathrm{CH}_{3} \mathrm{COC}_{2} \mathrm{H}_{5}$ & 72 & 9.5 \\
3-Pentanone & $\mathrm{C}_{2} \mathrm{H}_{5} \mathrm{COC}_{2} \mathrm{H}_{5}$ & 86 & 9.3 \\
Methane & $\mathrm{CH}_{4}$ & 16 & 12.6 \\
Ethane & $\mathrm{C}_{2} \mathrm{H}_{6}$ & 30 & 11.5 \\
Propane & $\mathrm{C}_{3} \mathrm{H}_{8}$ & 44 & 11.0 \\
Methyl formate & $\mathrm{HCOOCH}_{3}$ & 60 & 10.8 \\
Ethyl formate & $\mathrm{HCOOC}_{2} \mathrm{H}_{5}$ & 74 & 10.6 \\
Methyl acetate & $\mathrm{CH}_{3} \mathrm{COOCH}_{3}$ & 74 & 10.2 \\
Ethyl acetate & $\mathrm{CH}_{3} \mathrm{COOC}_{2} \mathrm{H}_{5}$ & 88 & 10.0 \\
Nitrogen & $\mathrm{N}_{2}$ & 28 & 15.6 \\
Oxygen & $\mathrm{O}_{2}$ & 32 & 12.06 \\
Carbon dioxide & $\mathrm{CO}_{2}$ & 44 & 13.8 \\
Carbon disulphide & $\mathrm{CS}_{2}$ & 76 & 10.0 \\
Carbon monoxide & $\mathrm{CO}$ & 28 & 14.0 \\
\hline
\end{tabular}


$\mathrm{C}_{2} \mathrm{H}_{4} \mathrm{OH}^{+}$; it also arises from $\mathrm{C}-\mathrm{H}$ bond dissociation in the parent ion. The dissociation channels are shown in eqs 1 and 2 [32].

$$
\begin{aligned}
& \mathrm{CH}_{3} \mathrm{OH}+\text { laser } \rightarrow\left(\mathrm{CH}_{3} \mathrm{OH}^{+}\right)^{*} \rightarrow \mathrm{CH}_{2} \mathrm{OH}^{+}+\mathrm{H} \\
& \mathrm{CH}_{3} \mathrm{CH}_{2} \mathrm{OH}+\text { laser } \rightarrow\left(\mathrm{CH}_{3} \mathrm{CH}_{2} \mathrm{OH}^{+}\right)^{*} \\
& \quad \rightarrow \mathrm{CH}_{3} \mathrm{CHOH}^{+}+\mathrm{H}
\end{aligned}
$$

The results for methanol and ethanol demonstrate that the cleavage of the $\mathrm{C}-\mathrm{H}$ bond easily occurs for alcohols. With these ionic fragments and their parent ions, precise identification of alcohols can be achieved with FLMS.

\section{Ketones}

Figure 2 shows the mass spectra of acetone, butanone, and 3-pentanone irradiated by $50 \mathrm{fs}$ laser pulses at an intensity of $6.0 \times 10^{13} \mathrm{~W} / \mathrm{cm}^{2}$. For acetone, the peak at $\mathrm{m} / \mathrm{q}=58$ is the parent ion $\mathrm{CH}_{3} \mathrm{COCH}_{3}{ }^{+}$, while the peak at $\mathrm{m} / \mathrm{q}=43$ is the ionic fragment $\mathrm{CH}_{3} \mathrm{CO}^{+}$; it results from direct cleavage of the $\mathrm{C}-\mathrm{C}$ bond of the parent ion. For butanone, the peak at $\mathrm{m} / \mathrm{z}=72$ is the parent ion $\mathrm{CH}_{3} \mathrm{COC}_{2} \mathrm{H}_{5}{ }^{+}$. The direct cleavage of the $\mathrm{C}-\mathrm{C}$ bond of the parent ion results in two ionic fragment $\mathrm{CH}_{3} \mathrm{CO}^{+}(\mathrm{m} / \mathrm{q}=43)$ and $\mathrm{C}_{2} \mathrm{H}_{5} \mathrm{CO}^{+}(\mathrm{m} / \mathrm{q}=$ 57). The yield of $\mathrm{CH}_{3} \mathrm{CO}^{+}$is much higher than that of $\mathrm{C}_{2} \mathrm{H}_{5} \mathrm{CO}^{+}$; this fact indicates that the removal of an ethyl radical is more favorable than that of a methyl radical for the parent ion $\mathrm{CH}_{3} \mathrm{COC}_{2} \mathrm{H}_{5}{ }^{+}$. For 3pentanone, the peak at $\mathrm{m} / \mathrm{q}=86$ is the parent ion $\mathrm{C}_{2} \mathrm{H}_{5} \mathrm{COC}_{2} \mathrm{H}_{5}{ }^{+}$. The peak at $\mathrm{m} / \mathrm{q}=57$ is the ionic fragment $\mathrm{C}_{2} \mathrm{H}_{5} \mathrm{CO}^{+}$, which results from the direct cleavage of the $\mathrm{C}-\mathrm{C}$ bond of the parent ion. The dissociation channels for these aliphatic ketones are summarized as follows:

$$
\begin{aligned}
& \mathrm{R}_{1} \mathrm{COR}_{2}+\text { laser } \rightarrow\left(\mathrm{R}_{1} \mathrm{COR}_{2}^{+}\right)^{*} \rightarrow \mathrm{R}_{1} \mathrm{CO}^{+} \\
& \quad+\mathrm{R}_{2} \text { or } \mathrm{R}_{1}+\mathrm{R}_{2} \mathrm{CO}^{+}
\end{aligned}
$$

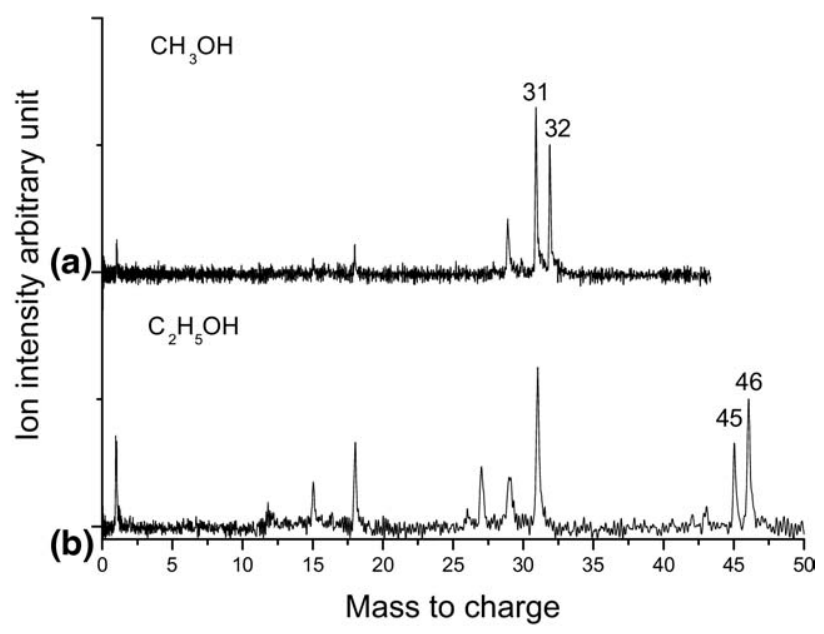

Figure 1. Mass spectra of (a) methanol and (b) ethanol irradiated by fs laser pulses.

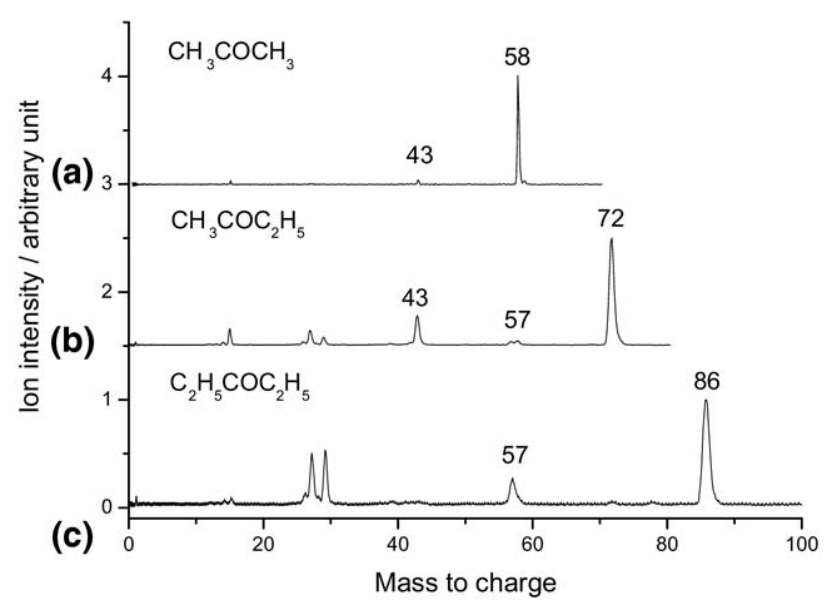

Figure 2. Mass spectra of (a) acetone, (b) butanone, (c) 3-pentanone irradiated by fs laser pulses.

$\mathrm{R}_{1}=\mathrm{R}_{2}=\mathrm{CH}_{3}$ for acetone, $\mathrm{R}_{1}=\mathrm{CH}_{3}$ and $\mathrm{R}_{2}=\mathrm{C}_{2} \mathrm{H}_{5}$ for butanone, $\mathrm{R}_{1}=\mathrm{R}_{2}=\mathrm{C}_{2} \mathrm{H}_{5}$ for 3-pentanone. The results demonstrate that the $\mathrm{C}-\mathrm{C}$ bond adjacent to the carbonyl group is easily broken for these ketone ions.

The degree of fragmentation can be controlled by adjusting the laser intensity. With the parent ion and some characteristic ionic fragments, we can identify these compounds with certainty. When the laser intensity is higher than $6.0 \times 10^{13} \mathrm{~W} / \mathrm{cm}^{2}$, all molecules in the laser focus are ionized. The ionization probability approaches unity for the above ketones [33]. Saturation ionization is helpful to determine the concentrations of molecules.

\section{Alkanes}

Figure 3 shows the mass spectra of methane, ethane, and propane irradiated by $7 \mathrm{fs}$ laser pulses at an intensity of about $1 \times 10^{14} \mathrm{~W} / \mathrm{cm}^{2}$. For methane, the peak at $\mathrm{m} / \mathrm{q}=16$ is the parent ion $\mathrm{CH}_{4}{ }^{+}$. The peak at $\mathrm{m} / \mathrm{q}=15$ is the ionic fragment $\mathrm{CH}_{3}{ }^{+}$, which arises from

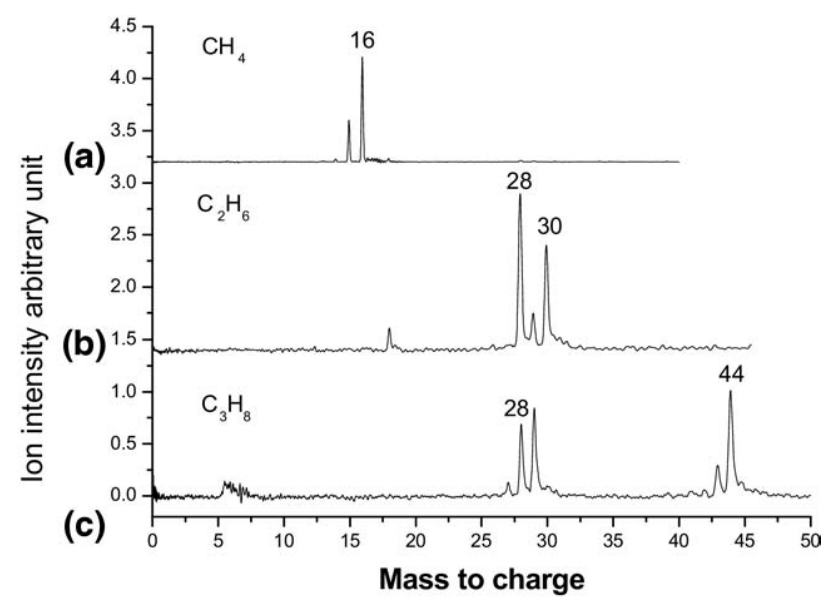

Figure 3. Mass spectra of (a) methane, (b) ethane, (c) propane irradiated by fs laser pulses. 
dissociation of the $\mathrm{C}-\mathrm{H}$ bond of the parent ion. For ethane, the peak at $\mathrm{m} / \mathrm{q}=30$ is the parent ion $\mathrm{C}_{2} \mathrm{H}_{6}{ }^{+}$. Hydrogen atom cleavage of the parent ion results in the ionic fragment $\mathrm{C}_{2} \mathrm{H}_{5}{ }^{+}(\mathrm{m} / \mathrm{q}=29)$. For propane, the peak at $\mathrm{m} / \mathrm{q}=44$ is the parent ion $\mathrm{C}_{3} \mathrm{H}_{8}{ }^{+}$. The peak at $\mathrm{m} / \mathrm{q}=43$ is the ionic fragment $\mathrm{C}_{3} \mathrm{H}_{7}{ }^{+}$, which results from the direct $\mathrm{C}-\mathrm{H}$ bond cleavage of the parent ion $\mathrm{C}_{3} \mathrm{H}_{8}{ }^{+}$.

From the above studies, we conclude that all saturated hydrocarbons studied here have a common dissociation channel, the hydrogen atom cleavage of the parent ion. The dissociation channel results in the ionic fragments $\mathrm{CH}_{3}{ }^{+}, \mathrm{C}_{2} \mathrm{H}_{5}{ }^{+}$, and $\mathrm{C}_{3} \mathrm{H}_{7}{ }^{+}$for methane, ethane, and propane, respectively. $\mathrm{C}_{2} \mathrm{H}_{4}{ }^{+}$is easily formed for ethane and propane. The formation channels are shown in eqs 4 and 5 .

$$
\begin{aligned}
& \mathrm{C}_{2} \mathrm{H}_{6}+\text { laser } \rightarrow\left(\mathrm{C}_{2} \mathrm{H}_{6}^{+}\right)^{*} \rightarrow \mathrm{C}_{2} \mathrm{H}_{4}^{+}+\mathrm{H}_{2} \\
& \mathrm{C}_{3} \mathrm{H}_{8}+\text { laser } \rightarrow\left(\mathrm{C}_{3} \mathrm{H}_{8}^{+}\right)^{*} \rightarrow \mathrm{C}_{2} \mathrm{H}_{4}^{+}+\mathrm{CH}_{4}
\end{aligned}
$$

\section{Esters}

Figure 4 shows the mass spectra of four esters, (Figure 4a) methyl formate, (Figure $4 \mathrm{~b}$ ) ethyl formate, (Figure 4c) methyl acetate, and (Figure 4d) ethyl acetate irradiated by strong fs laser pulses. The laser duration is 110 fs for methyl formate and ethyl acetate and $7 \mathrm{fs}$ for ethyl formate and methyl acetate. The laser intensity is $2 \times$ $10^{14} \mathrm{~W} / \mathrm{cm}^{2}$ for methyl formate and ethyl acetate and $1 \times 10^{14} \mathrm{~W} / \mathrm{cm}^{2}$ for ethyl formate and methyl acetate. For methyl formate, the peak at $\mathrm{m} / \mathrm{q}=60$ is the parent ion $\mathrm{HCOOCH}_{3}{ }^{+}$; for ethyl formate, the peak at $\mathrm{m} / \mathrm{q}=$ 74 is the parent ion $\mathrm{HCOOC}_{2} \mathrm{H}_{5}{ }^{+}$. For the mass spectra of $\mathrm{HCOOCH}_{3}$ and $\mathrm{HCOOC}_{2} \mathrm{H}_{5}$, there is a common peak at $\mathrm{m} / \mathrm{q}=31$ in addition to the parent ion. This peak can be identified as $\mathrm{CH}_{3} \mathrm{O}^{+}$, which is formed from a hydrogen migration progress in the excited electronic state of the parent ion, as shown in eq 6 :

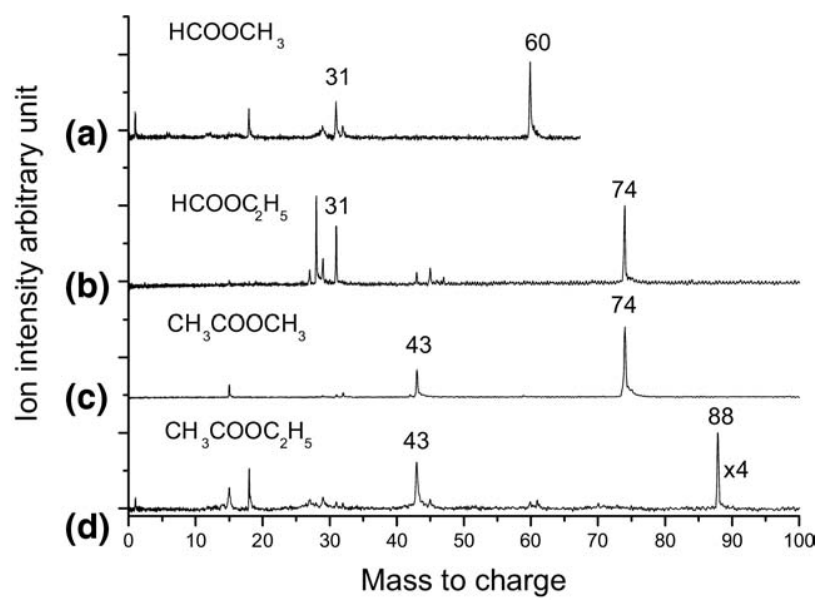

Figure 4. Mass spectra of (a) methyl formate, (b) ethyl formate, (c) methyl acetate, (d) ethyl acetate irradiated by fs laser pulses.

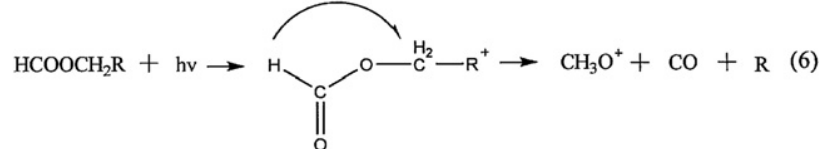

$\mathrm{R}$ represents $\mathrm{H}$ for $\mathrm{HCOOCH}_{3}$ and $\mathrm{CH}_{3}$ for $\mathrm{HCOOC}_{2} \mathrm{H}_{5}$. The above reaction is a characteristic dissociation process of formate esters [34].

For methyl acetate, the peak at $\mathrm{m} / \mathrm{q}=74$ is the parent ion $\mathrm{CH}_{3} \mathrm{COOCH}_{3}{ }^{+}$; for ethyl acetate, the peak at $\mathrm{m} / \mathrm{q}=88$ is the parent ion $\mathrm{CH}_{3} \mathrm{COOC}_{2} \mathrm{H}_{5}{ }^{+}$. For the mass spectra of methyl acetate and ethyl acetate, there is a common peak at $\mathrm{m} / \mathrm{q}=43$, which is $\mathrm{CH}_{3} \mathrm{CO}^{+}$[34]. This ion arises from dissociation of the $\mathrm{C}-\mathrm{O}$ bond of the parent ion. The process can be shown in formula 7 .

$$
\begin{aligned}
& \mathrm{CH}_{3} \mathrm{COOR}+\text { laser } \rightarrow \mathrm{CH}_{3} \mathrm{COOR}^{+} \\
& \quad \rightarrow \mathrm{CH}_{3} \mathrm{CO}^{+}+\mathrm{RO}
\end{aligned}
$$

$\mathrm{R}$ represents $\mathrm{CH}_{3}$ in $\mathrm{CH}_{3} \mathrm{COOCH}_{3}$ and $\mathrm{C}_{2} \mathrm{H}_{5}$ in $\mathrm{CH}_{3} \mathrm{COOC}_{2} \mathrm{H}_{5}$.

Ethyl formate and methyl acetate are isomeric compounds, and they have similar physical and chemical properties. If only the parent ion is produced, it is difficult to distinguish these compounds because of the same molecular mass. Fortunately, FLMS can provide some characteristic ionic fragments unlike PTR-MS. In intense fs laser fields, the molecule ionizes immediately and the parent ion may access some excited electronic states. The excited parent ion might dissociate into ionic fragments, which contain information about the molecular structure [34]. For the mass spectra of two isomers, ethyl formate and methyl acetate, the characteristic ionic fragment is $\mathrm{CH}_{3} \mathrm{O}^{+}$for the former and $\mathrm{CH}_{3} \mathrm{CO}^{+}$ for the latter. Thus, we can discriminate these two isomers easily with their different characteristic ionic fragments. With this property, FLMS is a powerful tool to discriminate isomers.

\section{Main Components of Air}

$\mathrm{N}_{2}, \mathrm{O}_{2}$, and $\mathrm{CO}_{2}$ are the main components of air, and also the major portion of the exhaled air of human beings. Their ionization energies are much higher than those of most VOCs. The tunneling ionization probability depends exponentially on the ionization energy for molecules in intense laser fields. A higher laser intensity is therefore needed to ionize air. Figure S1 in the Supplementary Information, which can be found in the electronic version of this article, shows the mass spectra of $\mathrm{N}_{2}, \mathrm{O}_{2}$, and $\mathrm{CO}_{2}$ irradiated by $7 \mathrm{fs}$ laser pulses at an intensity around $2 \times 10^{14} \mathrm{~W} / \mathrm{cm}^{2}$. Only parent ions are observed for these molecules.

The ionization energies of air are several electronvolts higher than those of VOCs. Therefore, the ionization probability of air is much lower than those of VOCs at the typical laser intensity for ionizing VOCs. For example, when the intensity of the $800 \mathrm{~nm}$ laser is $1 \times$ $10^{14} \mathrm{~W} / \mathrm{cm}^{2}$, the ionization probability is about $3 \%$ for 
nitrogen and $6 \%$ for oxygen [35]. However, the ionization probability approaches unity for ketones when the laser intensity reaches $6 \times 10^{13} \mathrm{~W} / \mathrm{cm}^{2}$ [33]. Assuming that the ionization probability of nitrogen and oxygen is one magnitude lower than that of VOCs and several ions are detected for one laser pulse, we can expect that about $10^{8}$ laser pulses will be needed to determine a specific VOC molecule at ppb levels if there will be no pretreatment of human breath air. This procedure will require several tens of hours even if $\mathrm{kHz}$ laser repetition is used. This is probably the major limitation for FLMS analysis of VOCs in human breath. However, a laser with a repetition rate of $6.2 \mathrm{MHz}$ and peak intensity of $2.3 \times 10^{14} \mathrm{~W} / \mathrm{cm}^{2}$ has recently become available in the laboratory [36]. VOCs at ppb level can be detected within $1 \mathrm{~min}$ with this type of laser. Therefore, FLMS will be able to quantify the concentrations of VOCs online without separating the VOCs from normal air when the high repetition and high power fs laser becomes commercially available.

\section{Other Pollutants of Air}

$\mathrm{CO}$ and $\mathrm{CS}_{2}$ are important pollutants of the atmosphere and the environment. Their concentrations are related to the quality of the atmosphere. Sometimes, these gaseous molecules are also contained in human breath. Figure S2 shows the mass spectra of $\mathrm{CO}$ and $\mathrm{CS}_{2}$ irradiated by $7 \mathrm{fs}$ laser pulses at an intensity around $2 \times$ $10^{14} \mathrm{~W} / \mathrm{cm}^{2}$. Strong parent ions are observed and some ionic fragments are produced with increasing laser intensity. Their concentrations can be directly determined by FLMS when the laser intensity is chosen to ensure that saturation ionization occurs.

From the above studies, we know all molecules can be ionized by intense fs laser pulses. The ionization probability is determined by the laser intensity and the ionization energy of the molecules. Depending on the laser intensity, the fragmentation can be controlled. Figure 5 show the mass spectra of methyl acetate at different laser intensities. When the laser intensity is $8 \times$ $10^{13} \mathrm{~W} / \mathrm{cm}^{2}$, a dominant parent ion $\mathrm{CH}_{3} \mathrm{COOCH}_{3}{ }^{+}$and a weak ionic fragment $\mathrm{CH}_{3} \mathrm{CO}^{+}$are observed. When the laser intensity is increased to $1.5 \times 10^{14} \mathrm{~W} / \mathrm{cm}^{2}$, the ionic fragment $\mathrm{CH}_{3} \mathrm{CO}^{+}$increases and $\mathrm{CH}_{3}{ }^{+}(\mathrm{m} / \mathrm{z}=15)$ appears. When the laser intensity reaches $5.5 \times 10^{14}$ $\mathrm{W} / \mathrm{cm}^{2}$, extensive ionic fragments appear. Because these ionic fragments are produced through the direct dissociation of the parent ion, they contain structural information for the molecule and are helpful for identifying molecules with the same molecular mass. In addition to laser intensity, pulse duration is also an important factor to determine the degree of fragmentation. In general, shorter pulse duration would result in less fragmentation. Clear patterns of parent ions and characteristic fragments allow FLMS to identify all components in human breath with certainty. When the laser intensity is higher than the value of the saturation ionization, all molecules in the laser focus are ionized. Thus, the concentrations of molecules can be

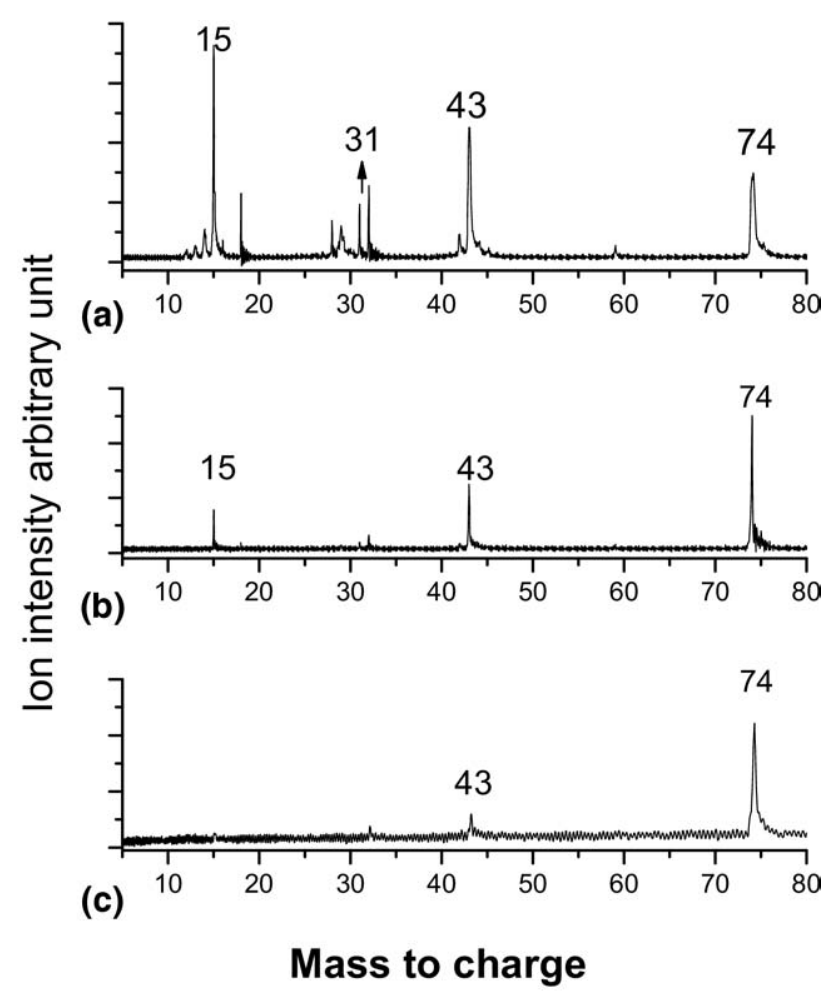

Figure 5. Mass spectra of methyl acetate at different laser intensity. (a) $5.5 \times 10^{14} \mathrm{~W} / \mathrm{cm}^{2}$, (b) $1.5 \times 10^{14} \mathrm{~W} / \mathrm{cm}^{2}$, (c) $0.8 \times 10^{14} \mathrm{~W} / \mathrm{cm}^{2}$.

precisely determined. Precise determination of the concentration for each VOC molecule will enable exhaled breath analysis to become a non-invasive diagnosis of complex diseases.

The goal of the current study was to determine the characteristic ionic peaks for each VOC irradiated by intense fs laser pulses. Thus, we can construct a database for all VOCs. Next, we will use FLMS to analyze a mixture of VOCs. The gaseous sample will be added to the vacuum chamber. The probability that the molecule interacts with the laser pulse is determined by its concentration in the mixture. Based on event-by-event recording, only a few molecules are ionized for each laser pulse by controlling the pressure and laser intensity. The ionized molecule can be precisely identified by comparison with the characteristic ionic peaks in the database. By counting how many laser pulses are needed for detecting each VOC, we can determine the concentration for each component in the mixture if the ionization probabilities for these molecules are known. Finally, we will use FLMS to analyze the components in human breath. There are several hundred types of molecules in human breath, most at ppb or ppt levels. From previous experience, we expect that about $10^{8}$ laser pulses will be needed to determine a specific component at ppb level. Therefore, high repetition and high power fs lasers are required for practical application of FLMS in analyzing VOCs in human breath. A laser with a repetition of $6.2 \mathrm{MHz}$ and peak intensity of $2.3 \times 10^{14} \mathrm{~W} / \mathrm{cm}^{2}$ has recently become 
available [36], allowing detection of VOCs at ppb level within 1 min. We believe that FLMS will be an important tool for human breath analysis when high repetition and high power fs lasers become commercially available.

\section{Conclusions}

We have studied the mass spectra of several kinds of VOCs irradiated by intense fs laser pulses. Dominant parent ions and some characteristic ionic fragments are observed for all molecules. The ionic fragments are generated by the direct dissociation of the parent ions and the degree of fragmentation can be controlled by adjusting the laser intensity. The characteristic ionic fragments are different for molecules with different geometric structures. These features enable FLMS to precisely identify many components in human breath, including isomers with the same molecular masses. In addition, FLMS can determine the concentrations of VOCs because saturation ionization can occur in intense fs laser fields. Therefore, FLMS can be a sensitive tool to quantify VOCs in human breath. Future research with high repetition and high power fs lasers will likely enable online detection of exhaled VOCs at the ppb level without prior separation of VOCs from normal air.

\section{Acknowledgments}

The authors acknowledge support for this work by the National Natural Science Foundation of China under grant nos. 10974005, 20637020, 10534010, and 10821062, and by the National Basic Research Program of China under grant no. 2006CB806007.

\section{Appendix A Supplementary Material}

Supplementary material associated with this article may be found in the online version at doi:10.1016/ j.jasms.2010.02.020.

\section{References}

1. Roukos, J.; Riffault, V.; Locoge, N.; Plaisance, H. VOC in an Urban and Industrial Harbor on the French North Sea Coast during Two Contrasted Meteorological Situations. Environ. Pollut. 2009, 157, 3001-3009.

2. Mentel, T. F.; Wildt, J.; Kiendler-Scharr, A.; Kleist, E.; Tillmann, R.; Dal Maso, M.; Fisseha, R.; Hohaus, Th.; Spahn, H.; Uerlings, R.; Wegener, R.; Griffiths, P. T.; Dinar, E.; Rudich, Y.; Wahner, A. Photochemical Production of Aerosols from Real Plant Emissions. Atmos. Chem. Phys. 2009, 9, 4387-4406.

3. Williams, J. E.; Scheele, M. P.; van Velthoven, P. F. J.; Cammas, J. P.; Thouret, V.; Galy-Lacaux, C.; Volz-Thomas, A. The Influence of Biogenic Emissions from Arica on Tropical Tropospheric Ozone During 2006: A Global Modeling Study. Atmos. Chem. Phys. 2009, 9, 5729-5749.

4. Oesterreich, R. C.; Siegrist, R. L. Quantifying Volatile Organic Compounds in Porous Media: Effects of Sampling Method Attributes, Contaminant Characteristics, and Environmental Conditions. Environ. Sci. Technol. 2009, 43, 2891-2898.

5. Delgado-Saborit, J. M.; Aquilina, N. J.; Meddings, C.; Baker, S.; Harrison, R. M. Model Development and Validation of Personal Exposure to Volatile Organic Compound Concentrations. Environ. Health Perspect. 2009, 117, 1571-1579.

6. Mo, J. H.; Zhang, Y. P.; Xu, Q. J.; Zhu, Y. F.; Lamson, J. J.; Zhao, R. Y. Determination and Risk Assessment of By-Products Resulting from Photocatalytic Oxidation of Toluene. Appl. Catal. B Environ. 2009, 89, $570-576$.
7. Irigaray, P.; Newby, J. A.; Clapp, R.; Hardell, L.; Howard, V.; Montagnier, L. S.; Epstein, S. D.; Belpomme, D. Lifestyle-Related Factors and Environmental Agents Causing Cancer: An Overview. Biomed. Pharmacother. 2007, 61, 640-658.

8. Buszewski, B.; Kesy, M.; Ligor, T.; Amann, A. Human Exhaled Air Analytics: Biomarkers of Diseases. Biomed. Chromatogr. 2007, 21, 553566.

9. Novak, B. J.; Blake, D. R.; Meinardi, S.; Rowland, F. S.; Pontello, A.; Cooper, D. M.; Galassetti, P. R. Exhaled Methyl Nitrate as a Noninvasive Marker of Hyperglycemia in Type 1 Diabetes. Proc. Natl. Acad. Sci. U.S.A. 2007, 104, 15613-15618.

10. Phillips, M.; Cataneo, R. N.; Ditkoff, B. A.; Fisher, P.; Greenberg, J.; Gunawardena, R.; Kwon, C. S.; Tietjf, O.; Cynthia, W. Prediction of Breast Cancer Using Volatile Biomarkers in the Breath. Breast Cancer Res. Treat. 2006, 99, 19-21.

11. Chen, X.; Xu, F. J.; Wang, Y.; Pan, Y. F.; Lu, D. J.; Wang, P.; Ying, K.; Chen, E. G.; Zhang, W. M. A Study of the Volatile Organic Compounds Exhaled by Lung Cancer Cells In Vitro for Breath Diagnosis. Cancer 2007, 110, 835-844.

12. Barker, M.; Hengst, M.; Schmid, J.; Buers, H. J.; Mittermainer, B.; Klemp, D.; Koppmann, R. Volatile Organic Compounds in the Exhaled Breath of Young Patients with Cystic Fibrosis. Eur. Respir. J. 2006, 27, 929-936.

13. Horvath, I.; Larzar, Z.; Gyulai, N.; Kollai, M.; Losconcyz, G. Exhaled Biomarkers in Lung Cancer. Eur. Respir. J. 2009, 34, 261-275.

14. Peng, G.; Tisch, U.; Adams, O.; Hakim, M.; Shehada, N.; Broza, Y. Y.; Billan, S.; Abdah-Bortnyak, R.; Kuten, A.; Haick, H. Diagnosing Lung Cancer in Exhaled Breath Using Gold Nanoparticles. Nature Nanotech. 2009, 4, 669-673

15. Phillips, M.; Altorki, N.; Austin, J. H. M.; Cameron, R. B.; Cataneo, R. N.; Kloss, R.; Maxfield, R. A.; Munawar, M. I.; Pass, H. I.; Rashid, A.; Rom, W. N.; Schmitt, P.; Wai, J. Detection of Lung Cancer Using Weighted Digital Analysis of Breath Biomarkers. Clin. Chim. Acta 2008, 393, 76-84.

16. Pauling, L.; Robinson, A. B.; Teranish, R.; Cary, P. Quantitative Analysis of Urine Vapor and Breath by Gas-Liquid Partition Chromatography. Proc. Natl. Acad. Sci. U.S.A. 1971, 68, 2374-2376.

17. Simth, D.; Spanel, P. Selected Ion Flow Tube Mass Spectrometry (SIFT-MS) for On-Line Trace Gas Analysis. Mass Spectrom. Rev. 2005, 24 , $661-700$.

18. Wehinger, A.; Schmid, A.; Mechtcheriakov, S.; Ledochowski, M.; Grabmer, C.; Gastl, G. A.; Amann, A. Lung Cancer Detection by Proton Transfer Reaction Mass-Spectrometric Analysis of Human Breath Gas. Int. J. Mass Spectrom. 2007, 265, 49-59.

19. Bajtarevic, A.; Ager, C.; Pienz, M.; Klieber, M.; Schwarz, K.; Ligor, M.; Ligor, T.; Filipiak, W.; Denz, H.; Fiegl, M.; Hilbe, W.; Weiss, W.; Lukas, P.; Jamnig, H.; Hackl, M.; Haidenberger, A.; Buszewski, B.; Miekisch, W.; Schubert, J.; Amann, A. Noninvasive Detection of Lung Cancer by Analysis of Exhaled Breath. Bio. Med. Central Cancer 2009, 9, 348.

20. Hankin, S. M.; Villeneuve, D. M.; Corkum, P. B.; Rayner, D. M. Nonlinear Ionization of Organic Molecules in High Intensity Laser Fields. Phys. Rev. Lett. 2000, 84, 5082-5085.

21. Tong, X. M.; Zhao, Z. X.; Lin, C. D. Theory of Molecular Tunneling Ionization. Phys. Rev. A 2002, 66, 033402.

22. Ledingham, K. W. D.; Singhal, R. P. High Intensity Laser Mass Spectrometry-A Review. Int. J Mass Spectrom. Ion Processes 1997, 163, 149-168.

23. Kilic, H. S.; Ledingham, K. W. D.; Kosmidis, C.; McCanny, T.; Singhal, R. P.; Wang, S. L.; Smith, D. J.; Langley, A. J.; Shaikh, W. Multiphoton Ionization and Dissociation of Nitromethane Using Femtosecond Laser Pulses at 375 and $750 \mathrm{~nm}$. J. Phys. Chem. A 1997, 101, 817-823.

24. Smith, D. J.; Ledingham, K. W. D.; Singhal, R. P.; Kilic, H. S.; McCanny, T.; Langley, A. J.; Taday, P. F.; Kosmidis, C. Time-of-Flight Mass Spectrometry of Aromatic Molecules Subjected to High Intensity Laser Beams. Rapid Commun. Mass Spectrom. 1998, 12, 813-820.

25. Hankin, S. M.; Tasker, A. D.; Robson, L.; Ledingham, K. W. D.; Fang, X.; McKenna, P.; Singhal, R. P.; Kosmidis, C.; Tzallas, P.; Jaroszynski, D. A.; Jones, D. R.; Issac, R. C.; Jamison, S. Femtosecond Laser Time-of-Flight Mass Spectrometry of Labile Molecular Analytes: Laser-Desorbed Nitro-Aromatic Molecules. Rapid Commun. Mass Spectrom. 2002, 16, 111-116.

26. Tanaka, M.; Panja, S.; Murakami, M.; Yatsuhashi, T.; Nakashima, N Intact Molecular Ion Formation of Cyclohexane and 2,3-Dimethy-1,3Butadiene by Excitation with a Short, Intense Femtosecond Laser Pulse. Chem. Phys. Lett. 2006, 427, 255-258.

27. Trushin, S. A.; Fu $\beta$, W.; Schmid, W. E. Dissociative Ionization at High Laser Intensities: Importance of Resonances and Relaxation for Fragmentation. J. Phys. B 2004, 37, 3987-4011.

28. Kim, S. K.; Guo, J.; Baskin, J.S.; Zewail, A. H. Femtosecond Chemically Activated Reactions: Concept of Nonstatistical Activation at High Thermal Energies. J. Phys. Chem. 1996, 100, 9202-9205.

29. Zhong, Q.; Poth, L.; Castleman, A. W. Ultrafast Dissociation Dynamics of Acetone: A Revisit to the S-1 State and 3s Rydberg State. J. Chem. Phys. 1999, 110, 192-196.

30. Wu, Z.; Wu, C.; Liang, Q.; Wang, S.; Liu, M.; Deng, Y.; Gong, Q. Fragmentation Dynamics of Methane by Few-Cycle Femtosecond Laser Pulses. J. Chem. Phys. 2007, 126, 074311.

31. Berkowitz, J.; Ellison, G. B.; Gutman, D. Three Methods to Measure RH Bond Energies. J. Phys. Chem. 1994, 98, 2744-2765. 
32. Ruscic, B.; Berkowitz, J. The Heats of Formation of Some C2h5o+ Isomers, Relevant Bond Energies in Ethanol and $\mathrm{Pa}(\mathrm{Ch} 3 \mathrm{cho})$. J. Chem. Phys. 1994, 101, 10936-10946.

33. Wu, C.; Xiong, Y.; Ji, N.; Gao, Z.; Kong, F. Field Ionization of Aliphatic Ketones by Intense Femtosecond Laser. J. Phys. Chem. A 2001, 105, 374-377.

34. Liu, M.; Wu, C.; Wu, Z.; Liang, Q.; Deng, Y.; Sun, Y.; Xu, Y.; Zhao, Y.; Liu, F.; Sheng, L. Mass Spectra of Methyl Acetate and Ethyl Formate. Chem. Phys. Lett. 2009, 468, 153-157.
35. Chu, X.; Chu, S. I. Role of the Electronic Structure and Multi-Electron Responses in Ionization Mechanisms of Diatomic Molecules in Intense Short-Pulse Lasers: An All-Electron Ab Initio Study. Phys. Rev. A 2004 70, 061402(R)

36. Liu, Y.; Tschuch, S.; Durr, M.; Rudenko, A.; Moshammer, R.; Ullrich, J.; Siegel, M.; Morgner, U. Towards Nonsequential Double Ionization of $\mathrm{Ne}$ and Ar Using a Femtosecond Laser Oscillator. Opt. Express 2007, 15, 18104-18110. 